\title{
Optic Nerve Measurement on MRI in the Pediatric Population: Normative Values and Correlations
}

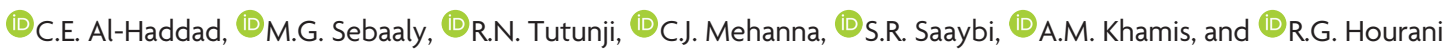

\begin{abstract}
BACKGROUND AND PURPOSE: Few articles in the literature have looked at the diameter of the optic nerve on MR imaging, especially in children, in whom observations are subjective and no normative data exist. The aim of this study was to establish a data base for optic nerve diameter measurements on MR imaging in the pediatric population.
\end{abstract}

MATERIALS AND METHODS: This was a retrospective study on the MR imaging of pediatric subjects (younger than 18 years of age) at the Department of Diagnostic Radiology at the American University of Beirut Medical Center, Beirut, Lebanon. The optic nerve measurements were obtained by 3 raters on axial and coronal sections at $3 \mathrm{~mm}$ (retrobulbar) and $7 \mathrm{~mm}$ (intraorbital) posterior to the lamina cribrosa.

RESULTS: Of 211 scans of patients (422 optic nerves), 377 optic nerves were measured and included. Ninety-four patients were female (45\%) and the median age at MR imaging was 8.6 years (interquartile range, 3.9-13.3 years). Optic nerves were divided into 5 age groups: $0-6$ months ( $n=18), 6$ months -2 years $(n=44), 2-6$ years $(n=86), 6-12$ years $(n=120)$, and 12-18 years $(n=109)$. An increase in optic nerve diameter was observed with age, especially in the first 2 years of life. Measurements did not differ with eye laterality or sex.

CONCLUSIONS: We report normative values of optic nerve diameter measured on MR imaging in children from birth to 18 years of age. A rapid increase in optic nerve diameter was demonstrated during the first 2 years of life, followed by a slower increase. This was independent of sex or eye laterality.

$\mathbf{T}$ he optic nerve anatomically starts from the optic disc and ends in the optic chiasm and comprises 4 distinct parts: the optic nerve head, the intraorbital portion, the intracanalicular portion, and the intracranial portion. ${ }^{1-3}$ Just posterior to the sclera, the nerve acquires arachnoid membranes continuous with those of the brain, ${ }^{4}$ composing the optic nerve sheath complex. While fundoscopy and optical coherence tomography can study the disc portion with high resolution, the remaining 3 portions are less accessible and require imaging studies, including MR imaging, sonography, and CT. ${ }^{5,6}$ In fact, MR imaging is superior due to its high soft-tissue resolution, the absence of ionizing radiation, and its high diagnostic accuracy as demonstrated by several studies evaluating the sensitivity of MR imaging compared with histopathologic examination in the detection of tumor invasion. ${ }^{7-9}$ According to Chawla et $\mathrm{al}^{7}$ and Schueler et $\mathrm{al}^{8}$ the MR imaging

Received May 23, 2017; accepted after revision September 13.

From the Departments of Ophthalmology (C.E.A.-H., C.J.M.), Diagnostic Radiology (M.G.S., R.N.T., A.M.K., R.G.H.), and Pediatrics (S.R.S.), American University of Beirut Medical Center, Beirut, Lebanon.

Please address correspondence to Roula Hourani, MD, Department of Diagnostic Radiology, American University of Beirut Medical Center, Cairo St, Hamra, Beirut, Lebanon; PO Box 11-0236, Riad El Solh, Beirut, Lebanon; e-mail: rh64@aub.edu.lb

http://dx.doi.org/10.3174/ajnr.A5456 sensitivity in detecting optic nerve abnormality is $60 \%-75 \%$, while its specificity is up to $90 \%$. Indeed, the optic nerve has been studied in healthy individuals and in pathologic states using MR imaging, CT, sonography, and cross-sectional anatomy. ${ }^{10-14}$ These studies, however, have reported either qualitative parameters ${ }^{5,15}$ or normative values of both the optic nerve and sheath as a complex. ${ }^{16-19}$

Ample literature exists on the use of MR imaging to classically describe the optic nerve sheath diameter, which has been associated with increased intracranial pressure from various causes like trauma, brain tumors, and idiopathic intracranial hypertension. Such studies are not sensitive to the optic nerve itself because measurements include the sheath, CSF, and optic nerve. Measurements of the optic nerve diameter have historically been difficult, due to problems in the methodology to be adopted, such as the differing appearance of the nerve sheath in the various MR imaging sequences and the width, which differs from anterior to posterior. With the use of new volumetric methods, thin-cut images, and the availability of fat-suppression sequences, such measurements can be accurately performed. Few articles in the literature have looked at the diameter of the optic nerve proper on MR imaging, especially in children, in whom observations are subjective and no normative data exist. Pathologic changes in the diam- 
eter of the optic nerve itself are not uncommonly encountered in different disease entities affecting the pediatric population, including optic nerve hypoplasia or atrophy, Leber optic neuropathy, multiple sclerosis, and optic nerve enlargement, such as from gliomas in neurofibromatosis type $1 .^{4,10,20-23}$ Measuring the optic nerve proper is essential to the diagnosis of such entities.

Our study aimed to report normative values for the optic nerve diameter on MR imaging in the pediatric population and examine its development across different age groups to generate a set of objective measurements for use by radiologists and ophthalmologists.

\section{MATERIALS AND METHODS \\ Patient Selection}

This was a retrospective review conducted at the Department of Diagnostic Radiology at the American University of Beirut Medical Center in Beirut, Beirut, Lebanon. The study was approved by the institutional review board, and informed consent was waived. We performed a thorough search on the institutional PACS for scans of patients younger than 18 years of age at the time of acquisition who underwent any MR imaging of the head and/or orbit with or without contrast enhancement between January 2010 and December 2015. Patients were divided into 5 age groups: younger than 6 months, 6 months to 2 years, 2-6 years, 6-12 years, and 12-18 years. We then reviewed patient charts and applied the following exclusion criteria: history of any brain or orbit tumor, enucleation of 1 eye, optic nerve lesions, enlargement or atrophy of the optic nerve, raised intracranial pressure (treated or not), and ischemia, hemorrhage, or atrophy along the optic pathway. We included patients who had indications for MR imaging other than optic nerve lesions, such as seizures and epilepsy, neck mass investigation, temporal bone abnormality, developmental delay, recurrent headaches, and others. Scans with poor visualization of the optic nerve were excluded.

\section{MR Imaging Measurements}

All MR images were performed on the Ingenia 3T or 1.5T systems (Philips Healthcare, Best, the Netherlands). The brain and orbit MRIs were performed with a 16-channel head coil. The sequences analyzed consisted of 2-mm sections. A T1-weighted inversion recovery sequence in the axial and coronal plane was performed with the following parameters: TR range $=5000-7000 \mathrm{~ms}$, TE range $=15-30 \mathrm{~ms}, \mathrm{TI}=400 \mathrm{~ms}$, matrix size range $=168 \times 100$ to $212 \times 130$, FOV range $=180 \times 180 \mathrm{~mm}$ to $230 \times 230 \mathrm{~mm}$, section thickness/spacing range $=2-0.3$ to $2-0.5 \mathrm{~mm}$, acquisition time $=5$ minutes 16 seconds; and an orbit-dedicated STIR sequence in the axial and coronal planes was performed with the following parameters: TR range $=2240-2650 \mathrm{~ms}$, TE range $=$ $80-90 \mathrm{~ms}, \mathrm{TI}=200 \mathrm{~ms}$, matrix size range $=256 \times 195$ to $320 \times$ 255 , FOV range $=200 \times 200 \mathrm{~mm}$ to $250 \times 250 \mathrm{~mm}$, section thickness/spacing range $=2-0.3 \mathrm{~mm}$ to $3-0.3 \mathrm{~mm}$, acquisition time $=2-3$ minutes. The axial images were obtained parallel to the intraorbital portion of the optic nerve, and the coronal images were placed on the sagittal cuts perpendicular to the optic nerves.

Image analysis and measurements were performed by a trained cognitive neuroscientist (R.N.T.), a senior radiology resident (M.G.S.), and a neuroradiologist (R.G.H.) using OsiriX Imaging Software (http://www.osirix-viewer.com) on a high-resolution monitor. The measurements were obtained on axial and coronal sections at 3 and 7 $\mathrm{mm}$ posterior to the lamina cribrosa. Measurements at $3 \mathrm{~mm}$ were retrobulbar, and measurements at $7 \mathrm{~mm}$ were at the midaspect of the intraorbital segment of the optic nerve (Fig 1). These 2 loci were chosen to examine whether the midaspect is smaller than the retrobulbar portion of the optic nerve. For every patient, each eye was treated individually. In some cases, on the axial or coronal cuts, 1 optic nerve was used for measurements, while the second one was not clearly delineated.

\section{Statistical Analysis}

All statistical analyses were performed with STATA 13 (StataCorp, College Station, Texas). The results were reported as mean $\pm \mathrm{SD}$. Interrater agreement was evaluated with intraclass correlation coefficients and corresponding 95\% confidence intervals to ensure reliability and reproducibility of the results. After confirming agreement among the 3 raters,
FIG 1. Axial $(A)$ and coronal STIR $(B)$ images of the orbits. An example of our measurement method. The optic nerve is measured without the nerve sheath, 3 (a) and 7 (b) $\mathrm{mm}$ posterior to the lamina cribrosa. It is also measured on the coronal plane (c) at the same 2 locations: retrobulbar and midaspect.

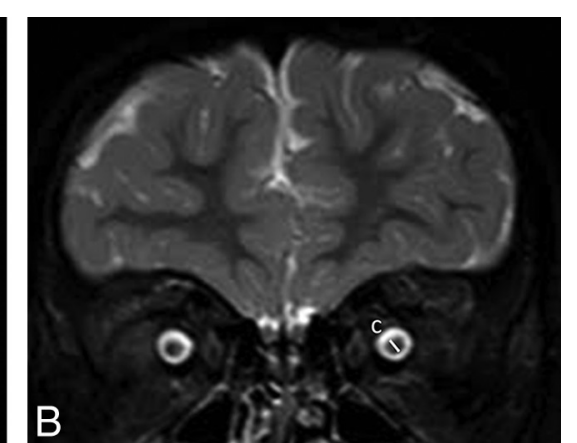

Table 1: Optic nerve diameter at each of the retrobulbar and midaspect locations on axial and coronal MRI sections

\begin{tabular}{|c|c|c|c|c|c|c|c|c|c|c|}
\hline & \multicolumn{5}{|c|}{ Sex } & \multicolumn{5}{|c|}{ Laterality } \\
\hline & \multicolumn{2}{|r|}{ Male } & \multicolumn{2}{|c|}{ Female } & \multirow[b]{2}{*}{$P$ Value } & \multicolumn{2}{|r|}{ Right } & \multicolumn{2}{|r|}{ Left } & \multirow[b]{2}{*}{$P$ Value } \\
\hline & No. & Mean $(\mathrm{mm})$ & No. & Mean (mm) & & No. & Mean (mm) & No. & Mean (mm) & \\
\hline \multicolumn{11}{|l|}{ Axial } \\
\hline Retrobulbar & 203 & $2.22 \pm 0.44$ & 158 & $2.20 \pm 0.41$ & .663 & 180 & $2.21 \pm 0.43$ & 181 & $2.22 \pm 0.43$ & .925 \\
\hline Midaspect & 176 & $1.53 \pm 0.40$ & 149 & $1.59 \pm 0.43$ & .223 & 160 & $1.56 \pm 0.43$ & 165 & $1.56 \pm 0.40$ & .923 \\
\hline \multicolumn{11}{|l|}{ Coronal } \\
\hline Retrobulbar & 182 & $2.28 \pm 0.58$ & 154 & $2.22 \pm 0.40$ & .270 & 168 & $2.25 \pm 0.50$ & 168 & $2.26 \pm 0.51$ & .820 \\
\hline Midaspect & 184 & $1.73 \pm 0.44$ & 149 & $1.76 \pm 0.42$ & .473 & 164 & $1.75 \pm 0.42$ & 169 & $1.74 \pm 0.45$ & .892 \\
\hline
\end{tabular}



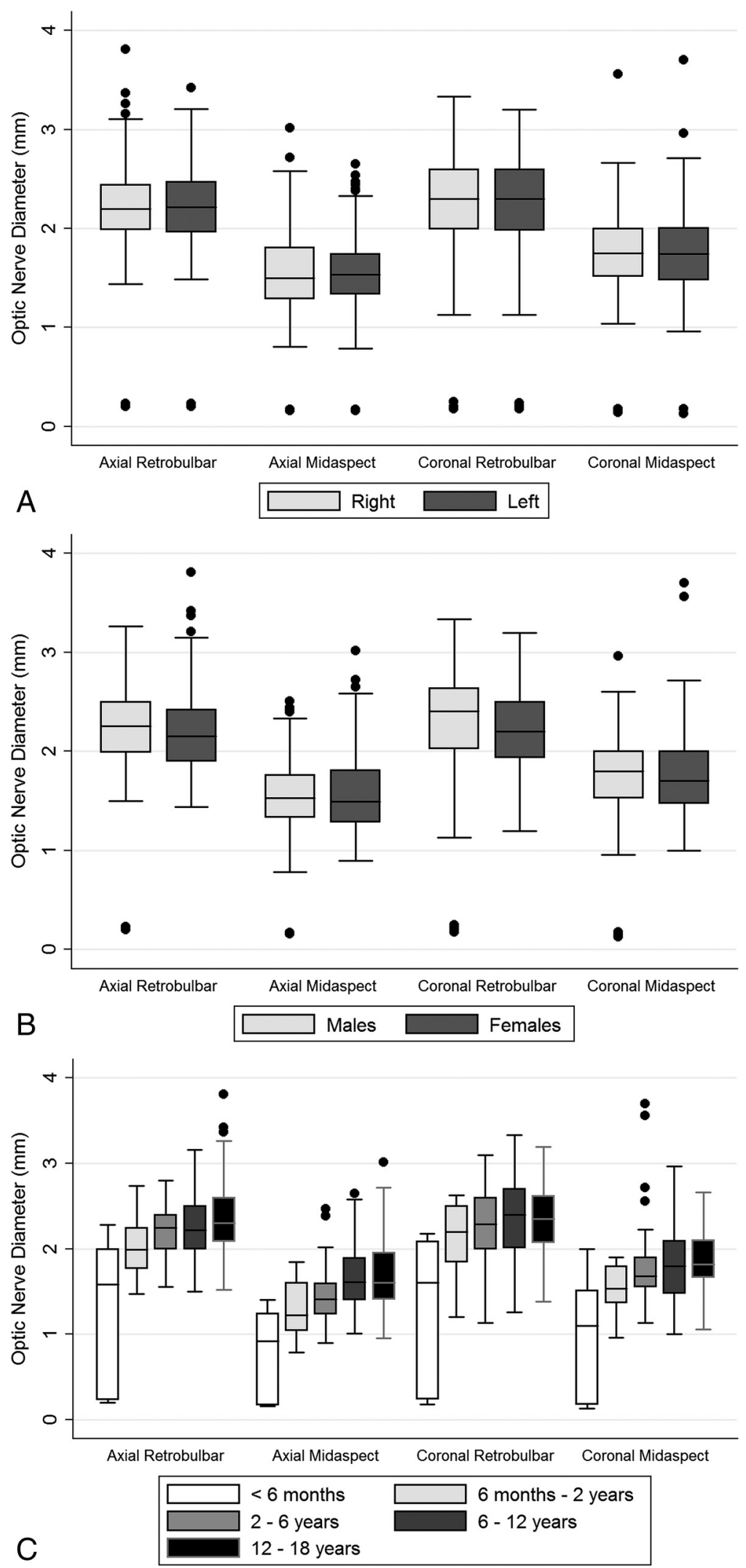

FIG 2. Optic nerve diameter measurements (millimeters) at each of the retrobulbar and midaspect locations on the axial and coronal MR imaging sections, according to eye laterality $(A)$, sex $(B)$, and age group (C). the right and left eyes were evaluated using the paired Student $t$ test or Wilcoxon signed rank test, and betweensex differences, with the unpaired $t$ test or Mann-Whitney $U$ test. ANOVA testing was performed to reveal between-group differences with a Šídák correction for multiple comparisons for more detailed results on confidence intervals and significances between each age group. Finally, measurement results were plotted versus age, and Pearson or Spearman correlation coefficients were calculated.

\section{RESULTS}

Two hundred eleven scans of patients were collected for measurement. The median age at MR imaging acquisition was 8.6 years (interquartile range, 3.9-13.3 years), and 94 (45\%) patients were females. Interrater agreement was excellent, with an intraclass correlation coefficient of 0.842 (95\% CI, 0.821-0.861; $P<.001$ ). The agreement between the readers for the patients younger than 6 months of age and children between 6 months and 2 years was good as well (intraclass correlation coefficient $=0.82$; 95\% CI, 0.579-0.931; $P<.001$; and intraclass correlation coefficient $=0.766$; 95\% CI, 0.693-0.823; $P<$ .001 , respectively).

Table 1 shows the optic nerve measurements on MR imaging at the retrobulbar and midaspect levels for each of the axial and coronal cuts. Optic nerve diameter measurements did not differ between the right and left eyes (Fig 2A) or between males and females (Fig 2B), regardless of the section and location of the measurement. However, the optic nerve significantly increased in diameter across age groups, which was also observed in all measurements (Fig 2C). At the axial cut, the mean diameter steadily increased with the age from $1.35 \pm 0.82$ $\mathrm{mm}$ among patients younger than 6 months up to $2.26 \pm 0.38 \mathrm{~mm}$ and $2.35 \pm 0.40 \mathrm{~mm}$ for patients between 6 and 12 years of age and between 12 and 18 years, respectively on the retrobulbar level (Table 2). Similarly, in the axial cuts, the mean diameter of the optic nerve increased with age from $0.73 \pm 0.55 \mathrm{~mm}$ among patients younger than 6 months we averaged the measurements. Data normality was assessed by the Shapiro-Wilk test for normality coupled with visual inspection of the data via histograms. Accordingly, differences between up to $1.67 \pm 0.36 \mathrm{~mm}$ for patients between 6 and 12 years of age and between 12 and 18 years of age and to $1.67 \pm 0.40 \mathrm{~mm}$ between 12 and 18 years of age on the midaspect level. 
Table 2: Optic nerve diameter measurements at each of the retrobulbar and midaspect locations on axial and coronal MRI sections

\begin{tabular}{|c|c|c|c|c|c|c|c|c|c|c|c|}
\hline & \multicolumn{11}{|c|}{ Age Group } \\
\hline & \multicolumn{2}{|r|}{$<6 \mathrm{mo}$} & \multicolumn{2}{|c|}{$6 \mathrm{mo}-2 \mathrm{yr}$} & \multicolumn{2}{|r|}{$2-6 y r$} & \multicolumn{2}{|r|}{$6-12 \mathrm{yr}$} & \multicolumn{2}{|r|}{$12-18 \mathrm{yr}$} & \multirow[b]{2}{*}{$P$ Value $^{\mathrm{a}}$} \\
\hline & No. & Mean (mm) & No. & Mean (mm) & No. & Mean (mm) & No. & Mean (mm) & No. & Mean (mm) & \\
\hline \multicolumn{12}{|l|}{ Axial } \\
\hline Retrobulbar & 13 & $1.35 \pm 0.82$ & 44 & $2.03 \pm 0.30$ & 86 & $2.20 \pm 0.30$ & 109 & $2.26 \pm 0.38$ & 109 & $2.35 \pm 0.40$ & $<.001$ \\
\hline Midaspect & 9 & $0.73 \pm 0.55$ & 31 & $1.30 \pm 0.33$ & 73 & $1.46 \pm 0.31$ & 114 & $1.67 \pm 0.36$ & 98 & $1.67 \pm 0.40$ & $<.001$ \\
\hline \multicolumn{12}{|l|}{ Coronal } \\
\hline Retrobulbar & 18 & $1.30 \pm 0.83$ & 29 & $2.08 \pm 0.44$ & 72 & $2.27 \pm 0.41$ & 113 & $2.37 \pm 0.44$ & 104 & $2.33 \pm 0.39$ & $<.001$ \\
\hline Midaspect & 18 & $0.99 \pm 0.66$ & 26 & $1.53 \pm 0.27$ & 69 & $1.79 \pm 0.43$ & 120 & $1.78 \pm 0.38$ & 100 & $1.87 \pm 0.32$ & $<.001$ \\
\hline
\end{tabular}

a $P$ value assessing the significance of the between-group comparisons using ANOVA.

Table 3: Two by 2 group comparisons of the optic nerve diameter measurements on different scans

\begin{tabular}{|c|c|c|c|c|}
\hline & $<6 \mathrm{mo}$ & $6 \mathrm{mo}-2 \mathrm{yr}$ & $2-6 y r$ & $6-12 \mathrm{yr}$ \\
\hline \multicolumn{5}{|l|}{$6 \mathrm{mo}-2 \mathrm{yr}$} \\
\hline \multicolumn{5}{|l|}{ Axial } \\
\hline $\mathrm{RB}$ & .196 & - & - & - \\
\hline MA & .225 & - & - & - \\
\hline \multicolumn{5}{|c|}{ Coronal } \\
\hline $\mathrm{RB}$ & $.026^{\mathrm{a}}$ & - & - & - \\
\hline MA & .453 & - & - & - \\
\hline \multicolumn{5}{|l|}{$2-6 y r$} \\
\hline \multicolumn{5}{|l|}{ Axial } \\
\hline $\mathrm{RB}$ & $<.001^{\mathrm{a}}$ & $.035^{\mathrm{a}}$ & - & - \\
\hline MA & $.010^{\mathrm{a}}$ & .626 & - & - \\
\hline \multicolumn{5}{|l|}{ Coronal } \\
\hline RB & $<.001^{\mathrm{a}}$ & .499 & - & - \\
\hline MA & $<.001^{\mathrm{a}}$ & $.049^{a}$ & - & - \\
\hline \multicolumn{5}{|l|}{$6-12 y r$} \\
\hline \multicolumn{5}{|l|}{ Axial } \\
\hline RB & $<.001^{\mathrm{a}}$ & $.003^{\mathrm{a}}$ & .999 & - \\
\hline MA & $<.001^{\mathrm{a}}$ & $<.001^{\mathrm{a}}$ & $.001^{a}$ & - \\
\hline \multicolumn{5}{|c|}{ Coronal } \\
\hline $\mathrm{RB}$ & $<.001^{\mathrm{a}}$ & $.032^{a}$ & .870 & - \\
\hline $\mathrm{MA}$ & $<.001^{a}$ & $.007^{a}$ & .999 & - \\
\hline \multicolumn{5}{|l|}{$12-18$ yr } \\
\hline \multicolumn{5}{|l|}{ Axial } \\
\hline RB & $<.001^{\mathrm{a}}$ & $<.001^{a}$ & .085 & .445 \\
\hline MA & $<.001^{\mathrm{a}}$ & $<.001^{\mathrm{a}}$ & $.002^{\mathrm{a}}$ & .999 \\
\hline \multicolumn{5}{|l|}{ Coronal } \\
\hline $\mathrm{RB}$ & $<.001^{\mathrm{a}}$ & .094 & .999 & .999 \\
\hline MA & $<.001^{\mathrm{a}}$ & $<.001^{\mathrm{a}}$ & .127 & .324 \\
\hline
\end{tabular}

Note:- RB indicates retrobulbar; MA, midaspect.

a $P$ value significant at .05 .

Significant between-group differences for all 4 measures were observed on 2 by 2 comparisons (Table 3 ). The results were then plotted in a measurement-versus-age comparison. The graphs show a steep increase in diameter in the first 2 years, after which the curve plateaus; this finding applied to both axial and coronal measurements and at the 2 loci, retrobulbar and midaspect. The most representative graph, obtained from midaspect measurements on the coronal cut plotted against age, is shown in Fig 3.

Most interestingly, there was a consistent difference in optic nerve diameters between the midaspect and retrobulbar portions, which was observed on both axial and coronal images and in most age groups.

\section{DISCUSSION}

In this study, we report normative values of optic nerve diameter measured on MR imaging in children from birth to 18 years of age, dividing them into 5 age groups: $0-6$ months, 6 months- 2 years, 2-6 years, $6-12$ years, and 12-18 years. Our results showed

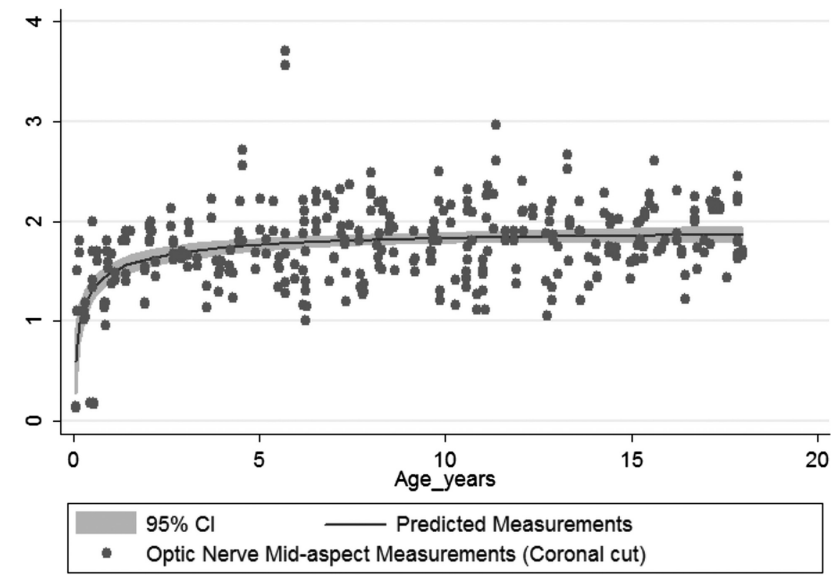

FIG 3. Optic nerve midaspect diameter growth with age on a coronal cut.

significant between-group differences in measurements, with a rapid increase in optic nerve diameter demonstrated during the first 2 years of life, followed by a slower increase to the 6 years of age with no significant change later. This was independent of sex or eye laterality.

Despite the technical challenges in the pediatric population, MR imaging was reliable in quantitatively assessing the size of the optic nerve proper. Multiple other studies have confirmed this finding with MR imaging for the diagnosis and early detection of optic nerve hypoplasia in children. ${ }^{18,22,24-27}$ However, there was no standardized method to obtain these measurements; thus, cross-study comparisons could not be performed accurately. Also, while there are reports on MR imaging measurements in healthy children, they focused on the optic nerve sheath complex as a whole and not the optic nerve itself. ${ }^{19,28}$ Therefore, there is a need to establish a standardized method for the measurement of the optic nerve on MR imaging in the pediatric population. These patients are at risk of multiple disease entities affecting the optic nerve, ${ }^{29}$ such as optic nerve hypoplasia or atrophy, optic neuritis, ${ }^{30,31}$ optic neuropathies, ${ }^{32}$ and other associated optic nerve pathology with failure to thrive. ${ }^{33}$ Objective assessment by MR imaging will aid in earlier and more accurate diagnoses of these various disorders in this vulnerable population.

Several studies have assessed the optic nerve sheath using various imaging modalities. This was mainly done to establish a normative data base in adults, ${ }^{5,10-14,27,28}$ or to use the optic nerve sheath complex as a surrogate to diagnose increased intracranial pressure. The latter outcome was studied both in children and using sonography, CT, or MR imaging and in different clinical 
settings. ${ }^{19,34-36}$ In fact, MR imaging proved to be superior to high-resolution ultrasonography and CT in demonstrating optic nerve measurements without the risks of exposure to ionizing radiation. ${ }^{11,27,37}$

Our results show that most of the optic nerve growth occurs in the first 2 years of life, which is in accordance with other published data regarding the early development of the optic nerve. In fact, the optic nerve increases in size in utero to reach normal neonate size at 36 weeks of gestation ${ }^{38}$; then, it continues to grow up to 2 years of age and less rapidly thereafter according to histologic studies. ${ }^{39,40}$ Ophthalmologists and radiologists ought to be aware of this finding while interpreting MR imaging scans in various clinical scenarios in infants with early signs of cerebral palsy, developmental delays, delayed visual maturation, and poor visual behavior/fixation. Hence, it is important to obtain normative measurements of the optic nerve diameter in the pediatric population; these measurements are very sensitive to age, especially in the first 2 years of life. Our data are also in agreement with other literature in that there was no laterality or sex differences in optic nerve thickness on MR imaging. ${ }^{41}$ The midaspect portion of the optic nerve would be expected to be thinner than the retrobulbar portion on both axial and coronal cuts, consistent with our reported results. This is a consequence of the optic nerve itself becoming more organized as it acquires its sheath traveling posteriorly through the narrow bony orbit. ${ }^{1,2}$

There are some limitations to this study. The relatively small sample size, particularly in the group of subjects younger than 2 years of age, could potentially affect the measurements. Moreover, these patients often require the administration of sedatives or general anesthesia, which may deviate their eyes from the primary position and may induce motion artifacts, which could explain the differences in measurement seen with changes in eye position and axial-versus-coronal cuts. The coronal cuts of the orbits were not obtained perpendicular to the axis of each optic nerve separately; this feature partly explains the difference in the measurements between the axial and coronal sections. Last, a prospective study with thorough general medical, neurologic, and ophthalmologic assessment of pediatric subjects before undergoing a standardized MR imaging examination of the orbit using the measurement criteria presented in this article is needed to confirm our findings.

\section{CONCLUSIONS}

We report normative values of the optic nerve diameter measured on MR imaging in children from birth to 18 years of age. A rapid increase in optic nerve diameter was demonstrated during the first 2 years of life followed by a slower increase. Our measurements can give radiologists and neuroscientists a reliable reference to diagnose optic nerve abnormalities in children.

\section{REFERENCES}

1. Duke-Elder S. System of Ophthalmology: The Anatomy of the Visual System. London: H. Kimpton; 1961

2. Rimmer S, Keating C, Chou T, et al. Growth of the human optic disk and nerve during gestation, childhood, and early adulthood. $\mathrm{Am} \mathrm{J}$ Ophthalmol 1993;116:748-53 CrossRef Medline

3. Selhorst JB, Chen Y. The optic nerve. Semin Neurol 2009;29:29-35 CrossRef Medline
4. Hayreh SS. Structure of the optic nerve. In: Hayreh SS. Ischemic Optic Neuropathies. Berlin: Springer-Verlag; 2011

5. Atta H. Imaging of the optic nerve with standardised echography. Eye 1988;2:358-66 CrossRef Medline

6. Smith MM, Strottmann JM. Imaging of the optic nerve and visual pathways. Semin Ultrasound CT MR 2001;22:473-87 CrossRef Medline

7. Chawla B, Sharma S, Sen S, et al. Correlation between clinical features, magnetic resonance imaging, and histopathologic findings in retinoblastoma: a prospective study. Ophthalmology 2012; 119:850-56 CrossRef Medline

8. Schueler A, Hosten N, Bechrakis N, et al. High resolution magnetic resonance imaging of retinoblastoma. $\mathrm{Br} \mathrm{J} \mathrm{Ophthalmol} \mathrm{2003;87:}$ 330-35 CrossRef Medline

9. Sirin S, Schlamann M, Metz KA, et al. High-resolution MRI using orbit surface coils for the evaluation of metastatic risk factors in 143 children with retinoblastoma, part 1: MRI vs. histopathology. $\mathrm{Neu}$ roradiology 2015;57:805-14 CrossRef Medline

10. Parravano JG, Toledo A, Kucharczyk W. Dimensions of the optic nerves, chiasm, and tracts: MR quantitative comparison between patients with optic atrophy and normals. J Comp Assis Tomogr 1993; 17:688-90 CrossRef Medline

11. Hesselink J, Karampekios S. Normal computed tomography and magnetic resonance imaging anatomy of the globe, orbit, and visual pathways. Neuroimaging Clin N Am 1996;6:15-27 Medline

12. Ozgen A, Aydingöz U. Normative measurements of orbital structures using MRI. J Comp Assis Tomogr 2000;24:493-96 Medline

13. Ozgen A, Ariyurek M. Normative measurements of orbital structures using CT. AJR Am J Roentgenol 1998;170:1093-96 CrossRef Medline

14. Goeres P, Zeiler FA, Unger B, et al. Ultrasound assessment of optic nerve sheath diameter in healthy volunteers. J Crit Care 2016;31: 168-71 CrossRef Medline

15. Ossoinig K, Cennamo G, Frazier-Byrne S. Echographic differential diagnosis of optic-nerve lesions. In: Thijssen JM, Verbeek AM, eds. Ultrasonography in Ophthalmology. Documenta Ophthalmologica Proceedings Series. Vol 29. Dordrech: Springer; 1981

16. Miller DH, Newton MR, Van der Poel J, et al. Magnetic resonance imaging of the optic nerve in optic neuritis. Neurology 1988;38: 175-75 CrossRef

17. Wilejto M, Shroff M, Buncic J, et al. The clinical features, MRI findings, and outcome of optic neuritis in children. Neurology 2006;67: 258-62 CrossRef Medline

18. Hickman SJ, Toosy AT, Jones SJ, et al. A serial MRI study following optic nerve mean area in acute optic neuritis. Brain 2004;127:2498505 CrossRef Medline

19. Shofty B, Ben-Sira L, Constantini S, et al. Optic nerve sheath diameter on MR imaging: establishment of norms and comparison of pediatric patients with idiopathic intracranial hypertension with healthy controls. AJNR Am J Neuroradiol 2012;33:366-69 CrossRef Medline

20. Trip SA, Schlottmann PG, Jones SJ, et al. Optic nerve atrophy and retinal nerve fibre layer thinning following optic neuritis: evidence that axonal loss is a substrate of MRI-detected atrophy. Neuroimage 2006;31:286-93 CrossRef Medline

21. Skarf B, Hoyt CS. Optic nerve hypoplasia in children: association with anomalies of the endocrine and CNS. Arch Ophthalmol 1984; 102:62-67 CrossRef Medline

22. Hellström A, Wiklund L-M, Svensson E. Diagnostic value of magnetic resonance imaging and planimetric measurement of optic disc size in confirming optic nerve hypoplasia. J AAPOS 1999;3: 104-08 CrossRef Medline

23. Avery RA, Mansoor A, Idrees R, et al. Optic pathway glioma volume predicts retinal axon degeneration in neurofibromatosis type 1 . Neurology. 2016;87:2403-07 CrossRef Medline

24. Lenhart PD, Desai NK, Bruce BB, et al. The role of magnetic resonance imaging in diagnosing optic nerve hypoplasia. Am J Ophthalmol 2014;158:1164-71.e2 CrossRef Medline

25. Yiannakas MC, Wheeler-Kingshott CA, Berry AM, et al. A method 
for measuring the cross sectional area of the anterior portion of the optic nerve in vivo using a fast 3D MRI sequence. J Magn Reson Imaging 2010;31:1486-91 CrossRef Medline

26. Kalantari H, Jaiswal R, Bruck I, et al. Correlation of optic nerve sheath diameter measurements by computed tomography and magnetic resonance imaging. Am J Emerg Med 2013;31:1595-97 CrossRef Medline

27. Steinborn M, Fiegler J, Kraus V, et al. High-resolution ultrasound and magnetic resonance imaging of the optic nerve and the optic nerve sheath: anatomic correlation and clinical importance. Ultraschall Med 2011;32:608-13 CrossRef Medline

28. Steinborn M, Friedmann M, Hahn H, et al. Normal values for transbulbar sonography and magnetic resonance imaging of the optic nerve sheath diameter (ONSD) in children and adolescents. Ultraschall Med 2015;36:54-58 CrossRef Medline

29. Taylor D. Developmental abnormalities of the optic nerve and chiasm. Eye 2007;21:1271-84 CrossRef Medline

30. Manogaran P, Vavasour IM, Lange AP, et al. Quantifying visual pathway axonal and myelin loss in multiple sclerosis and neuromyelitis optica. Neuroimage Clin 2016;11:743-50 CrossRef Medline

31. Buch D, Savatovsky J, Gout O, et al. Combined brain and anterior visual pathways' MRIs assist in early identification of neuromyelitis optica spectrum disorder at onset of optic neuritis. Acta Neurologica Belg 2017;117:67-74 CrossRef Medline

32. Bansal NK, Hagiwara M, Borja MJ, et al. Influence of clinical history on MRI interpretation of optic neuropathy. Heliyon 2016;2:e00162 CrossRef Medline

33. Birkebæk NH, Patel L, Wright NB, et al. Optic nerve size evaluated by magnetic resonance imaging in children with optic nerve hypopla- sia, multiple pituitary hormone deficiency, isolated growth hormone deficiency, and idiopathic short stature. J Pediatr 2004;145: 536-41 CrossRef Medline

34. Geeraerts T. Noninvasive surrogates of intracranial pressure: another piece added with magnetic resonance imaging of the cerebrospinal fluid thickness surrounding the optic nerve. Crit Care 2013; 17:187 CrossRef Medline

35. Geeraerts T, Newcombe VF, Coles JP, et al. Use of T2-weighted magnetic resonance imaging of the optic nerve sheath to detect raised intracranial pressure. Crit Care 2008;12:R114 CrossRef Medline

36. Le A, Hoehn ME, Smith ME, et al. Bedside sonographic measurement of optic nerve sheath diameter as a predictor of increased intracranial pressure in children. Ann Emerg Med 2009;53785-91 CrossRef Medline

37. Giger-Tobler C, Eisenack J, Holzmann D, et al. Measurement of optic nerve sheath diameter: differences between methods? A pilot study. Klin Monbl Augenheilkd 2015;232:467-70 CrossRef Medline

38. Haratz K, Viñals F, Lev D, et al. Fetal optic nerve sheath measurement as a non-invasive tool for assessment of increased intracranial pressure. Ultrasound Obstet Gynecol 2011;38:646-51 CrossRef Medline

39. Dolman CL, McCormick AQ, Drance SM. Aging of the optic nerve. Arch Ophthalmol 1980;98:2053-58 CrossRef Medline

40. Magoon EH, Robb RM. Development of myelin in human optic nerve and tract: a light and electron microscopic study. Arch Ophthalmol 1981;99:655-59 CrossRef Medline

41. Oyama J, Mori K, Imamura M, et al. Size of the intracranial optic nerve and optic tract in neonates at term-equivalent age at magnetic resonance imaging. Pediatr Radiol 2016;46:527-33 CrossRef Medline 